DEMOGRAPHIC RESEARCH

VOLUME 33, ARTICLE 8, PAGES 211-238

PUBLISHED 21 JULY 2015

http://www.demographic-research.org/Volumes/Vol33/8/

DOI: 10.4054/DemRes.2015.33.8

Research Article

Ideation and intention to use contraceptives in Kenya and Nigeria

Stella Babalola

Neetu John

Bolanle Ajao

Ilene S. Speizer

(C) 2015 Babalola, John, Ajao \& Speizer.

This open-access work is published under the terms of the Creative Commons Attribution NonCommercial License 2.0 Germany, which permits use, reproduction \& distribution in any medium for non-commercial purposes, provided the original author(s) and source are given credit.

See http://creativecommons.org/licenses/by-nc/2.0/de/ 


\section{Table of Contents}

1 Introduction 212

$2 \quad$ Objectives 215

3 Methods 216

3.1 Participants 216

3.2 Variables 216

3.3 Analysis 219

$\begin{array}{lll}3.4 & \text { Hypotheses tested } & 219\end{array}$

$4 \quad$ Findings $\quad 219$

4.1 Dimensions of ideation 220

4.1.1 Kenya 220

4.1.2 Nigeria 222

4.2 Association of dimensions of ideation with intention to use 223

4.2.1 Kenya 223

$\begin{array}{lll}4.2 .2 & \text { Nigeria } & 226\end{array}$

5 Discussion $\quad 227$

6 Conclusion 231

References $\quad 232$ 


\title{
Ideation and intention to use contraceptives in Kenya and Nigeria
}

\author{
Stella Babalola ${ }^{1}$ \\ Neetu John ${ }^{2}$ \\ Bolanle Ajao ${ }^{2}$ \\ Ilene S. Speizer ${ }^{3}$
}

\begin{abstract}
BACKGROUND

Contraceptive use remains low to moderate in most African countries. Ideation, or the ideas and views that people hold, has been advanced as a possible explanation for differences in contraceptive use within and across countries.
\end{abstract}

\section{OBJECTIVES}

In this paper, we sought to identify the relevant dimensions of ideation and assess how these dimensions relate to contraceptive use intentions in two illustrative countries, Kenya and Nigeria.

\section{METHODS}

Using factor analysis, we first identified the relevant dimensions of ideation from a set of cognitive, emotional, and social interaction items. Subsequently, we examined the relationships of these dimensions with intention to use contraceptives.

\section{RESULTS}

The data revealed four dimensions of contraceptive ideation in both countries: perceived self-efficacy, myths and rumors related to contraceptives, social interactions and influence, and contraceptive awareness. All four dimensions of ideation are strongly associated with contraceptive use intention in Nigeria. Only perceived selfefficacy was significantly associated with contraceptive use intention in Kenya.

\footnotetext{
${ }^{1}$ Corresponding author: Center for Communication Programs, Johns Hopkins University. 111 Market Place. Baltimore, MD 21202. U.S.A. Tel.: +1410-659-6232. E-Mail: sbabalol@jhusph.edu.

${ }^{2}$ Center for Communication Programs, Johns Hopkins University. Baltimore, MD, U.S.A.

${ }^{3}$ Carolina Population Center, University of North Carolina at Chapel Hill, Chapel Hill, U.S.A, and Department of Maternal and Child Health, University of North Carolina at Chapel Hill Gillings School of Global Public Health, Chapel Hill, NC, U.S.A.
} 


\section{CONCLUSION}

The ideation model is relevant for contraceptive use research and programing. Programs seeking to increase contraceptive use and help women to attain their desired family size should prioritize promotion of contraceptive self-efficacy. In addition, in countries with low contraceptive prevalence, programs should seek to identify ways to correct prevailing myths and rumors, increase contraceptive awareness, and promote positive social interactions around contraceptive use.

\section{Introduction}

Contraceptive use is a key factor in preventing unwanted pregnancies, reducing maternal and child mortality, and improving the lives of women and their families (Cleland et al. 2012; Kavanaugh and Anderson 2013; Sonfield et al. 2013; Tsui, McDonald-Mosley, and Burke 2010). A recent study estimated that contraceptive use could avert more than two-fifths of maternal deaths (Ahmed et al. 2012). Increased access to contraceptive services has been established as a cost-effective strategy for countries to reduce maternal and child mortality (Moreland and Talbird 2006). The benefits of contraceptive use go beyond the health sector. Providing unrestricted access to contraceptives will help ensure a reduction in unwanted pregnancies and thereby contribute to increased female education, women's empowerment, poverty reduction, and even environmental sustainability (Moreland and Talbird 2006; Smith et al. 2009; Sonfield et al. 2013).

Regrettably, levels of contraceptive use remain low in many African countries: unintended pregnancies are common, and unmet need is high. In Nigeria, for example, the results of the 2013 Demographic and Health Survey indicate that only 15.1\% of married women were using any contraceptive method, while only $9.8 \%$ were using a modern method (NPC/ICF 2014). These numbers have not changed meaningfully since 2003 (NPC/ICF 2009). Partly as a result of low contraceptive use, in 2013 fertility remained high in Nigeria at 5.5 children per women, on average. Underlying the low contraceptive use and high fertility rate in Nigeria are fertility preferences that favor a large family size. Only $19 \%$ of currently married women desired no more children while 33\% desired another child within the next two years (NPC/ICF 2014). Furthermore, the mean ideal family size was 7.1 children per women while unmet need stood at $16 \%$ among currently married women.

Kenya's reproductive health context is different from the situation in Nigeria. The total fertility rate was 4.6 children per woman in 2008 (KNBS/ICF 2010). In 2008, 39\% of married Kenyan women were using modern contraceptive methods, a noticeable 
increase from 32\% in 2003 (KNBS/ICF 2010). In addition, in 2008, 49\% of married women in Kenya desired no more children while $27 \%$ would want to wait at least two years for another child (KNBS/ICF 2010). The mean ideal number of children among married women in Kenya, 4.0 children per woman, was lower than the actual fertility rate, while $26 \%$ had an unmet need for family planning.

Clearly, the two countries are different, not only in terms of fertility but also in terms of unmet need and fertility desires. Comparing the context of high fertility and low contraceptive use in Nigeria to Kenya, which has lower fertility (but still higher than replacement level at 2.1) and higher contraceptive use, is useful when examining the role of social influences on family planning norms and practices, which is the focus of this paper.

In this paper we examine differences and commonalities in the determinants of contraceptive use intentions in these two contexts with a special focus on ideational variables. Ideation can be defined as "views and ideas that people hold individually" (van de Kaa 1996: 423). These views and ideas reflect individuals' ways of thinking; the media and social interactions contribute to shaping these views and ideas (Kincaid 2000a).

The suggestion that ideational change or changes in the way people think is a key factor in fertility decline is not new: more than a century ago, Leroy-Beaulieu attributed fertility decline to changing moral values (Leroy-Beaulieu 1896). Nonetheless, it was not until the 1980s that ideational change gained prominence in demographic literature as an explanation for fertility decline and to add nuance to the classical demographic transition theory (Bongaarts and Watkins 1996; Cleland 1985; Cleland and Wilson 1987; Lesthaeghe 1983; Lesthaeghe and Surkyn 1988; van de Kaa 1996). Some studies have posited ideational change to be a key factor in the second demographic transition in Europe (van de Kaa 2002; Lesthaeghe 2010; Sobotka, Zeman, and Kantorová 2003) and in recent fertility declines in some less industrialized countries (e.g., AbbasiShavazi, McDonald, and Hosseini-Chavoshi 2009 for Iran).

We build on a model proposed by Lawrence Kincaid that links individual ideation with behavior, the Ideation Model of Strategic Communication and Behavior Change (Kincaid 2000a). Our model (Figure 1) includes some psychosocial variables that were not in the original Kincaid model but which research has shown to be closely associated with behaviors, including interpersonal communication and perceived social support. Kincaid (2000a) pointed out that the inferences made by demographers on the role of ideation in fertility decline have been indirect, relying mostly on spatial patterns of fertility decline. To correct for this weakness, he proposed an ideational model that can be measured and tested at the individual level by elucidating the psychological and social interaction pathways of behavior change. Such a conceptualization broadens 
understanding of the micro-level decision-making processes that affect contraceptive use behaviors and facilitate fertility change (Kincaid 2000a).

Figure 1: Ideation model of strategic communication and behavior change

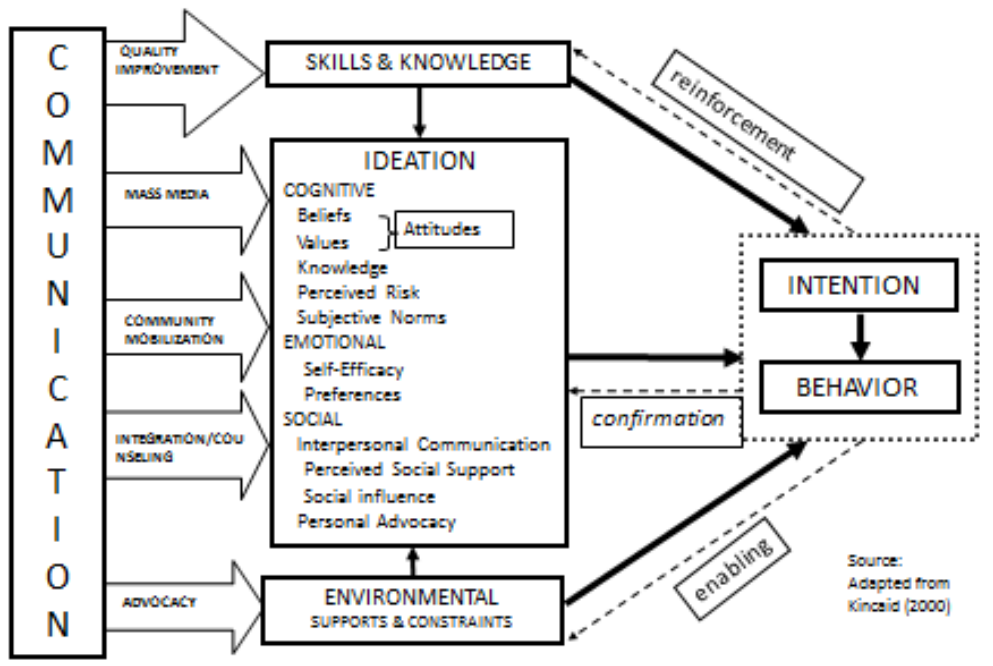

Kincaid posits that ideation is an intermediate construct between behavior and contextual factors. He argues that ideation comprises three domains: cognitive, emotional, and elements of social interactions. The cognitive dimension includes the following psychosocial concepts: attitudes, knowledge, perceived risk, subjective norms, and self-image. The emotional domain includes preferences and self-efficacy. Lastly, the social elements of ideation include social support, social influence, interpersonal communication (e.g., spousal communication), and personal advocacy (Babalola and Kincaid 2009; Kincaid 2000a, 2000b). Individually, these ideational variables have been recognized in other domains as influencing behaviors and are key components of several behavior change models (Fishbein et al. 2001).

Research has shown that, on their own, these ideational elements affect contraceptive intention and use. For example, several studies have found a significant relationship between spousal communication (social interaction dimension in Kincaid's model) and increased contraceptive use (Agha and Van Rossem 2004; Gayen and Raeside 2010; Link 2011; Tumlinson et al. 2013). Some studies have also found a positive significant relationship between personal or perceived spousal approval of family planning (social interaction dimension) and use of contraceptive methods 
(Kaggwa, Diop, and Storey 2008; Rahayu, Utomo, and McDonald 2009; Samandari, Speizer, and O’Connell 2010; Teye 2013). Moreover, research has shown that perceived normative support and perceived peer behavior (social interaction dimension) are strong determinants of intention to use and actual use of contraceptives (Gayen and Raeside 2010; Ryan, Franzetta, and Manlove 2007; Samandari, Speizer, and O’Connell 2010). Other studies have found that positive attitudes towards contraception (cognitive dimension) increase the likelihood of using a method (Bryant 2009; Khumsaen and Gary 2009; Potard et al. 2012). By contrast, negative attitudes such as fear of side effects or perceived disadvantages of contraceptive use have been linked with lack of intention to use and lower use (Bajwa et al. 2012; Bosompra 2001). A high level of perceived self-efficacy (or confidence in one's ability to act; emotional dimension) to use contraception has been positively associated with intention to use, increased likelihood of contraceptive adoption, and sustained use (Agha 2010; Bogale, Boer, and Seydel 2010; Khumsaen and Gary 2009; Ryan, Franzetta, and Manlove 2007; Taffa et al. 2002). In analyses that have created an index of ideation, higher ideation scores have been shown to be associated with increased contraceptive use (Amouzou and Becker 2009; Babalola and Vonrasek 2005; Kincaid 2000a,b).

\section{Objectives}

With the theoretical background described above in mind and using Kenya and Nigeria as illustrative countries, the objectives of this paper are twofold. First, we will identify the relevant dimensions of contraceptive ideation in urban Kenya and Nigeria to determine the similarities and differences between these two contexts. Second, we will explore the association of the identified dimensions of ideation with intention to use contraceptives among married or in-union women in these settings. Two reasons informed the decision to focus on contraceptive intention. First, intention has been posited in many theories of behavior change as the most proximate determinant of actual behavior (e.g., Fishbein et al. 2001). Also, many studies have found intention to be a very strong determinant of behavior (Curtis and Westoff 1996; Bankole and Westoff 1998; Roy et al. 2003). Second, in the absence of longitudinal data, the focus on the association of ideation with intention to use as opposed to actual contraceptive use allows us to better address possible reverse causality inherent in cross-sectional data. Ideation relates to people's perceptions now, whereas behavioral intentions relate to how people see themselves in the future. It is therefore reasonable to argue that ideation affects contraceptive intentions rather than the other way around. 


\section{Methods}

\subsection{Participants}

The results presented in this manuscript are based on cross-sectional household surveys conducted by the Measurement, Learning \& Evaluation project as part of a comprehensive strategy to evaluate the effects of the Nigeria Urban Reproductive Health Initiative (NURHI) and the Tupange, the Urban Reproductive Health Project in Kenya. Funded by the Bill \& Melinda Gates Foundation, both NURHI and Tupange seek to generate demand for family planning services and increase the contraceptive prevalence rate in selected cities with a special focus on the urban poor. The data analyzed were derived from the 2010 baseline surveys that targeted women aged 15 49 years in six large cities in Nigeria (Abuja, Benin City, Ibadan, Ilorin, Kaduna, and Zaria), and in five cities in Kenya (Nairobi, Kisumu, Mombasa, Kakamega, and Machakos). Survey participants comprised 16,144 respondents in Nigeria and 8,932 in Kenya. A two-stage sample selection process was used to select the participants. First, fieldworkers selected clusters in each survey city, with the number selected proportional to the size of the city. All households and dwelling units within the selected clusters were listed and a random sample of 41 households (Nigeria) or 30 households (Kenya) was selected for the women's interview. The women's questionnaire was administered to all eligible women (ages 15-49) in the selected households who consented to be interviewed. We limited the analyses to married or in union women who reported awareness of at least one contraceptive method, not currently using a modern contraceptive method, and who reported no intention to be pregnant within the next 12 months. This consisted of a sample of 1,570 women in Kenya and 4,511 women in Nigeria.

\subsection{Variables}

The key dependent variable assessed in this study is reported intention to use a modern contraceptive method within 12 months of the survey. The key independent variables were dimensions of contraceptive ideation derived from 31 ideational items measured similarly in each of the two study countries. The items included awareness (spontaneous or probed) of various modern methods of contraception ranging from sterilization to emergency contraception (8 items; used as proxy for knowledge and classified under the cognitive dimension of ideation). The items also included a set of eight items that measured myths and rumors about contraceptives using Likert-scale questions that assessed the respondents' level of disagreement with statements such as 
"women who use contraception end up with health problems" (attitudes; classified under the cognitive dimension of ideation). The individual items were coded such that higher scores reflect rejection of myths and rumors. Perceived self-efficacy to take action regarding contraceptive use consisted of seven items measured on a Likert scale that assessed the respondent's confidence in their ability to take specific actions, including start a conversation on family planning with their partner and obtain a method if they decided to use contraception (emotional dimension of ideation). In addition, we also measured discussion of FP with significant others, including mother, mother-inlaw, and sister-in-law (3 items; social interaction dimension of ideation) and perceived approval of significant others for the respondent's use of contraceptives (5 items; social interaction dimension of ideation). In preliminary factor analysis models we had included other variables, but the final model only retained the variables that loaded significantly on any factor in either of the two study countries.

In addition to ideation, we controlled for education level, age, square of age, parity, city of residence, religion, religiosity, husband's education, age gap between spouses, women's autonomy measured as whether or not the woman needed permission from the husband or anyone else before using contraceptives (this potential ideational item did not load on any ideational factor in either of the two study countries so is only included as a control variable), prior use of contraceptives, and household wealth. Summary statistics for these variables can be found in Table 1.

Table 1: Summary statistics (percentages and means) of key sociodemographic variables of urban married or cohabiting women, not currently using contraceptives and not desiring to be pregnant within the next 12 months, Kenya 2010, Nigeria 2010

\begin{tabular}{lcc}
\hline & Kenya (n=1570) & Nigeria (n=4511) \\
\hline Education Level (\%) & 5.6 & 20.7 \\
None & 49.0 & 22.2 \\
Primary & 35.9 & 39.9 \\
Secondary & 10.5 & 17.2 \\
Post-secondary & 28.9 & 32.4 \\
\hline Current age in years & 2.2 & 3.8 \\
\hline Parity (mean) & & $\mathrm{n} / \mathrm{a}$ \\
\hline City of residence (\%) & 66.6 & \\
Nairobi & 24.7 & \\
Mombasa & 5.8 & \\
Kisumu & 1.0 & \\
Machakos & 1.9 & \\
Kakamega & & \\
\hline
\end{tabular}


Table 1: (Continued)

\begin{tabular}{|c|c|c|}
\hline & Kenya $(n=1570)$ & Nigeria $(n=4511)$ \\
\hline City of residence (\%) & $\mathrm{n} / \mathrm{a}$ & \\
\hline Abuja & & 9.3 \\
\hline Benin City & & 9.9 \\
\hline Ibadan & & 18.2 \\
\hline llorin & & 17.8 \\
\hline Kaduna & & 22.7 \\
\hline Zaria & & 22.0 \\
\hline \multicolumn{3}{|l|}{ Religion (\%) } \\
\hline Non-Muslim & 85.8 & 38.2 \\
\hline Muslim & 14.2 & 61.8 \\
\hline \multicolumn{3}{|l|}{ Religiosity (\%) } \\
\hline Not very religious & 36.8 & 23.9 \\
\hline Very religious & 63.2 & 76.1 \\
\hline \multicolumn{3}{|l|}{ Husband's education $^{1}(\%)$} \\
\hline None & 1.9 & 13.7 \\
\hline Primary & 28.0 & 16.3 \\
\hline Secondary & 52.9 & 40.0 \\
\hline Post-secondary & 17.2 & 30.0 \\
\hline Age gap between spouses in years ${ }^{2}$ (mean) & 6.0 & 9.7 \\
\hline \multicolumn{3}{|l|}{ Fertility desires (\%) } \\
\hline Desire an additional child & 58.0 & 69.5 \\
\hline Does not desire additional child & 42.0 & 30.5 \\
\hline \multicolumn{3}{|l|}{ Prior use of contraceptives (\%) } \\
\hline No & 32.3 & 59.5 \\
\hline Yes & 67.7 & 40.5 \\
\hline \multicolumn{3}{|l|}{ Woman's autonomy (\%) } \\
\hline Does not need permission for FP & 55.9 & 21.5 \\
\hline Needs permission for FP & 44.1 & 78.5 \\
\hline
\end{tabular}

Notes: $\mathrm{n} / \mathrm{a}=$ Not applicable.

${ }^{1 .}$ For women who reported that they did not know their husband's education level, we assign the median level of husband's education in the sample.

2. For women who reported that they did not know their or their husband's age, we assign the mean age gap in the sample. 


\subsection{Analysis}

We employed two analytic methods in this study. First, we used factor analysis to determine the relevant dimensions of ideation. We relied on scree plots and the interpretability of the factors to determine the appropriate number of factors. We chose a cut-off point of 0.40 for factor loadings to determine the significance of items for each factor. We scored the respondents on each of the derived orthogonal factors.

Second, we used the derived factor scores as a continuous variable along with other independent variables in multivariable logistic regression models to predict contraceptive use intention. We estimated two models for each country, one that included only the socio-demographic and household variables (Model 1) and the second that included the independent variables from Model 1 as well as dimensions of ideation (Model 2). We reported the odds ratio associated with each correlate (Models 1 and 2) and the X-standardized beta coefficients to enable us to see the relative importance of the independent variables (Model 2 only). All results adjust for the complex sampling design and use weights to adjust for non-response and sample selection.

\subsection{Hypotheses tested}

The two hypotheses tested in this paper are as follows:

i. Given differences in contraceptive prevalence and unmet need, we posit that the socio-demographic and household variables that are associated with contraceptive intention differ between Kenya and Nigeria.

ii. All the dimensions of ideation are significant predictors of contraceptive intention in both Kenya and Nigeria.

\section{Findings}

Table 1 presents the socio-demographic characteristics of the study population: married women not currently using a contraceptive method with awareness of at least one contraceptive method. In Kenya the mean age of the women is 28.9 years. Almost half of the women have post-primary education, while most reside in Nairobi city, are nonMuslim, and are very religious. More than two-fifths of the women desire no more children. The mean age gap between these women and their husbands is six years and many of these husbands (70.1\%) have post-primary education. More than two-fifths (44.1\%) of the women reported needing permission before using family planning. 
In Nigeria the mean age is 32.4 years. Very few women reside in the capital city. Many of the women have post-primary education, are Muslim, and are very religious. About three-quarters of the women desire to have an additional child at some point in the future. The mean spousal age gap is 9.7 years and $70.0 \%$ of the husbands have postprimary education. About four-fifths of the women need permission before using family planning.

\subsection{Dimensions of ideation}

\subsubsection{Kenya}

Results of the scree plot suggested that a four-factor solution was ideal. Three items did not load significantly on any of the four factors (Table 2). Nonetheless, the four factors explained $92.7 \%$ of the variance in the data.

The first factor explained $37.6 \%$ of the variance in the data and measured perceived self-efficacy to take actions that favor contraceptive use (see Table 2). The seven items that loaded most significantly on this factor had a Cronbach's alpha score of 0.845 . The second factor explained $25.6 \%$ of the variance and represented myths and rumors about contraceptives. The eight items that loaded most significantly on this factor were related to beliefs about the dangerous health and social consequences of contraceptives on the woman and her unborn child. These eight items had a Cronbach's alpha score of 0.804 . The third factor reflected social interactions and social influence and explained $15.4 \%$ of the variance; eight items related to discussion of FP with significant others and their perceived support of the respondent's use of contraceptives loaded most significantly on this factor. The Cronbach's alpha for these nine variables was 0.735 . The fourth factor explained $14.1 \%$ of the variance; eight items that loaded most significantly on this factor measured awareness about specific contraceptive methods. These items had a Cronbach's alpha of 0.687. 
Table 2: Dimensions of ideation and factor loading of ideational items among married women, non-users of contraceptives, Kenya and Nigeria

\begin{tabular}{|c|c|c|}
\hline Factor/Items & Kenya & Nigeria \\
\hline Factor 1: Perceived self-efficacy & $\begin{array}{c}\text { Variance } \\
\text { explained }=37.6 \%\end{array}$ & $\begin{array}{c}\text { Variance } \\
\text { explained }=37.4 \%\end{array}$ \\
\hline $\begin{array}{l}\text { Perceived self-efficacy for starting a conversation } \\
\text { with partner about FP }\end{array}$ & 0.671 & 0.804 \\
\hline $\begin{array}{l}\text { Perceived self-efficacy for convincing partner that } \\
\text { they should use a FP method }\end{array}$ & 0.702 & 0.813 \\
\hline $\begin{array}{l}\text { Perceived self-efficacy for obtaining a FP method if } \\
\text { decided to use one }\end{array}$ & 0.787 & 0.798 \\
\hline $\begin{array}{l}\text { Perceived self-efficacy for using a FP method even if } \\
\text { partner doesn't want you to }\end{array}$ & 0.450 & 0.511 \\
\hline $\begin{array}{l}\text { Perceived self-efficacy for using a FP method even if } \\
\text { no friend or neighbor uses }\end{array}$ & 0.709 & 0.734 \\
\hline $\begin{array}{l}\text { Perceived self-efficacy for using a FP method even if } \\
\text { religious leader did not think she should }\end{array}$ & 0.691 & 0.628 \\
\hline $\begin{array}{l}\text { Perceived self-efficacy for getting to a place where } \\
\text { contraceptives are provided if needed }\end{array}$ & 0.726 & 0.830 \\
\hline Factor 2: Myths and rumors & $\begin{array}{c}\text { Variance } \\
\text { explained }=25.6 \%\end{array}$ & $\begin{array}{c}\text { Variance } \\
\text { explained }=27.3 \%\end{array}$ \\
\hline $\begin{array}{l}\text { Disagreed that use of contraceptive injection can } \\
\text { make a woman sterile }\end{array}$ & 0.566 & 0.666 \\
\hline $\begin{array}{l}\text { Disagreed that people who use contraception end up } \\
\text { with health problems }\end{array}$ & 0.688 & 0.701 \\
\hline Disagreed that contraceptives can harm your womb & 0.704 & 0.747 \\
\hline $\begin{array}{l}\text { Disagreed that contraceptives reduce women's } \\
\text { sexual urge }\end{array}$ & 0.428 & 0.568 \\
\hline Disagreed that contraceptives can cause cancer & 0.599 & 0.662 \\
\hline $\begin{array}{l}\text { Disagreed that contraceptives can give you } \\
\text { deformed babies }\end{array}$ & 0.640 & 0.687 \\
\hline $\begin{array}{l}\text { Disagreed that contraceptives are dangerous to your } \\
\text { health }\end{array}$ & 0.738 & 0.668 \\
\hline $\begin{array}{l}\text { Disagreed that women who use FP may become } \\
\text { promiscuous }\end{array}$ & ns & 0.457 \\
\hline
\end{tabular}


Table 2: (Continued)

\begin{tabular}{lcc}
\hline \multicolumn{1}{c}{ Factor/ltems } & Kenya & Nigeria \\
\hline Factor 3: Social interactions and influence & $\begin{array}{c}\text { Variance } \\
\text { explained }=15.4 \%\end{array}$ & $\begin{array}{c}\text { Variance } \\
\text { explained }=15.8 \%\end{array}$ \\
Discussed FP with mother & 0.401 & $\mathrm{~ns}$ \\
Discussed FP with mother-in-law & 0.423 & 0.416 \\
Discussed FP with sister-in-law & 0.447 & 0.400 \\
Perceived that mother would support her use of & 0.557 & 0.526 \\
contraceptives & & \\
Perceived that mother-in-law would support her use & 0.691 & 0.699 \\
of contraceptives & & \\
Perceived that sister-in-law would support her use of & 0.610 & 0.613 \\
contraceptives & & \\
Perceived that father-in-law would support her use of & 0.448 & 0.537 \\
contraceptives & & \\
Perceived that religious leader would support her & 0.425 & 0.450 \\
use of contraceptives & & Variance \\
\hline Factor 4: Contraceptive awareness & Variance & 0.531 \\
& explained=14.1\% & explained=13.8\% \\
Aware of female sterilization & 0.598 & 0.492 \\
Aware of male sterilization & 0.561 & 0.491 \\
Aware of oral pill & 0.440 & 0.499 \\
Aware of IUD & 0.576 & 0.440 \\
Aware of injectables & 0.401 & 0.495 \\
Aware of implants & 0.566 & 0.409 \\
Aware of female condoms & $\mathrm{ns}$ & 0.405 \\
Aware of LAM & $\mathrm{ns}$ & \\
\hline
\end{tabular}

Note: ns = not significant

\subsubsection{Nigeria}

Based on the scree plot and for interpretability of the results, we determined that a fourfactor solution was ideal. One item did not load significantly on any of the four factors (Table 2). As we observed for Kenya, the first factor measured perceived self-efficacy for taking actions that favor contraceptive use. This first factor explained $37.4 \%$ of the variance in the data. The seven items that load significantly on this factor had a Cronbach alpha of 0.889 . The second factor was related to myths and rumors about contraceptives. The proportion of the variance explained by this factor was $27.3 \%$. Eight items loaded most significantly on this factor; the Cronbach's alpha was 0.851 . 
The third factor can be labeled social interactions and social influence; it explained $15.8 \%$ of the variance in the data. The eight items that loaded most significantly on this factor had a Cronbach's alpha of 0.716. The fourth factor measured aspects of contraceptive awareness and explained $13.8 \%$ of the variance in the data; eight items loaded significantly on this factor with a Cronbach's alpha of 0.692 .

\subsection{Association of dimensions of ideation with intention to use contraceptive}

\subsubsection{Kenya}

Among the women included in the study, 36.0\% (95\% CI: 30.7\%, 41.5\%) reported an intention to use a modern method in the next 12 months. Intention to use a modern method varied between 23.8\% in Mombasa, 49.1\% in Kisumu, and 50.9\% in Machakos (Table not shown).

The results of Model 1 (Table 3) reveal significant differences by city of residence. Compared to the women resident in Nairobi, the women from Kakamega are $78 \%$ more likely and those from Machakos more than twice as likely to report intention to use contraceptives. The results of this model further show that the odds of intention to use contraceptives are about 63\% lower for Muslims than for non-Muslims. Religiosity, education, prior contraceptive use, household wealth, women's autonomy, fertility desires, and husband's education are not significantly related to intention to use contraception.

The introduction of the dimensions of ideation into the estimated model (Model 2) reveals some changes in the strength of the relationship of intention with sociodemographic and household variables compared to what we found in Model 1. Specifically, city of residence and religion have become less significant, while parity is now significant. The results of Model 2 further show that only one of the four dimensions of ideation is significantly and positively associated with contraceptive use intention: perceived self-efficacy. In particular, women with higher self-efficacy are more likely to intend to use a method compared to their peers with lower perceived selfefficacy. Judging from the standardized beta coefficients, the self-efficacy dimension contributes more to explaining contraceptive use intention than any of the other three dimensions. 
Table 3: Results of logistic regression models of the relationship of intention to use contraception with socio-demographic variables and dimensions of ideation, Current non-users, married/in-union women, Kenya and Nigeria

\begin{tabular}{|c|c|c|c|c|c|c|}
\hline \multirow{3}{*}{ Variable } & \multicolumn{3}{|c|}{ Kenya $(n=1570)$} & \multicolumn{3}{|c|}{ Nigeria $(n=4511)$} \\
\hline & \multicolumn{2}{|c|}{ Model 1} & Model 2 & \multicolumn{2}{|c|}{ Model 1} & \multirow{2}{*}{$\begin{array}{l}\text { Model } 2 \\
\text { Std. } \beta \text { coef. }\end{array}$} \\
\hline & OR & OR & Std. $\beta$ coef. & OR & OR & \\
\hline \multicolumn{7}{|c|}{ Socio-demographic and household variables } \\
\hline \multicolumn{7}{|c|}{ Education Level } \\
\hline None (RC) & 1.00 & 1.00 & 0.00 & 1.00 & 1.00 & 0.00 \\
\hline Primary & 0.937 & 0.742 & -0.149 & $1.367 \dagger$ & 1.315 & 0.114 \\
\hline Secondary & 0.666 & 0.518 & -0.313 & $1.510^{*}$ & 1.288 & 0.124 \\
\hline Post-secondary & 0.848 & 0.580 & -0.167 & $1.515 \dagger$ & 1.111 & 0.040 \\
\hline Current age in years & 1.175 & 1.183 & 1.386 & $1.485^{\star \star \star}$ & $1.459 * \star \star$ & $3.086^{* * *}$ \\
\hline Square of age & $0.996^{\star}$ & $0.995^{\star}$ & $-2.358^{\star}$ & $0.992^{\star \star \star}$ & $0.993^{\star \star \star}$ & $-3.960^{\star \star \star}$ \\
\hline Parity & 1.136 & $1.174^{*}$ & $0.313^{*}$ & $1.097^{\star \star}$ & $1.106^{\star \star}$ & $0.273^{\star \star}$ \\
\hline \multicolumn{7}{|l|}{ City of residence (Kenya) } \\
\hline Nairobi (RC) & 1.00 & 1.00 & 0.00 & & & \\
\hline Mombasa & 0.790 & 0.756 & -0.121 & & & \\
\hline Kisumu & 1.366 & 1.322 & 0.066 & & & \\
\hline Machakos & $2.343^{\star \star *}$ & $2.064^{\star *}$ & $0.070^{\star \star}$ & & & \\
\hline Kakamega & $1.782^{* *}$ & $1.619^{\star}$ & $0.065^{\star}$ & & & \\
\hline \multicolumn{7}{|l|}{ City of residence (Nigeria) } \\
\hline Abuja & & & & 1.00 & 1.00 & 0.00 \\
\hline Benin City & & & & 1.018 & 0.928 & -0.022 \\
\hline Ibadan & & & & $0.454^{\star \star \star}$ & $0.444^{\star \star \star}$ & $-0.314^{\star \star \star}$ \\
\hline Ilorin & & & & 0.693 & $0.667 \dagger$ & $-0.155 \dagger$ \\
\hline Kaduna & & & & $0.580^{*}$ & $0.549^{*}$ & $-0.251^{*}$ \\
\hline Zaria & & & & $0.585^{*}$ & $0.612^{*}$ & $-0.204^{*}$ \\
\hline \multicolumn{7}{|l|}{ Religion } \\
\hline Non-Muslim (RC) & 1.00 & 1.00 & 0.00 & 1.00 & 1.00 & 0.00 \\
\hline Moslem & $0.375^{\star \star}$ & $0.404^{*}$ & $-0.316^{*}$ & $1.288 \dagger$ & $1.655^{\star \star}$ & $0.245^{\star \star}$ \\
\hline \multicolumn{7}{|l|}{ Religiosity } \\
\hline Not very religious (RC) & 1.00 & 1.00 & 0.00 & 1.00 & 1.00 & 0.00 \\
\hline Very religious & 0.961 & 0.970 & -0.015 & $0.785 \dagger$ & $0.753^{*}$ & $-0.121^{*}$ \\
\hline
\end{tabular}


Babalola et al.: Ideation and intention to use contraceptives in Kenya and Nigeria

Table 3: (Continued)

\begin{tabular}{|c|c|c|c|c|c|c|}
\hline \multirow{3}{*}{ Variable } & \multicolumn{3}{|c|}{ Kenya (n=1570) } & \multicolumn{3}{|c|}{ Nigeria $(n=4511)$} \\
\hline & \multicolumn{2}{|c|}{ Model 1} & Model 2 & \multicolumn{2}{|c|}{ Model 1} & \multirow{2}{*}{$\begin{array}{l}\text { Model } 2 \\
\text { Std. } \beta \text { coef. }\end{array}$} \\
\hline & OR & OR & Std. $\beta$ coef. & OR & OR & \\
\hline \multicolumn{7}{|l|}{ Fertility desires } \\
\hline Desire an additional child (RC) & 1.00 & 1.00 & 0.00 & 1.00 & 1.00 & 0.00 \\
\hline Does not desire additional child & 0.994 & 0.933 & -0.034 & $3.346^{* * *}$ & $2.045^{\star \star \star}$ & $0.330^{* * *}$ \\
\hline \multicolumn{7}{|l|}{ Husband's education } \\
\hline None (RC) & 1.00 & 1.00 & 0.00 & 1.00 & 1.00 & 0.00 \\
\hline Primary & 1.504 & 1.256 & 0.102 & $1.698^{*}$ & $1.542 \dagger$ & $0.160 \dagger$ \\
\hline Secondary & 1.800 & 1.552 & 0.220 & $1.477 \dagger$ & 1.360 & 0.151 \\
\hline Post-secondary & 1.115 & 1.067 & 0.025 & $1.772^{\star}$ & $1.718^{*}$ & $0.248^{*}$ \\
\hline Age gap between spouses in years & 0.973 & 0.975 & -0.125 & 0.987 & 0.990 & -0.070 \\
\hline \multicolumn{7}{|l|}{ Woman's autonomy } \\
\hline \multicolumn{7}{|l|}{ Does not need permission for FP } \\
\hline$(\mathrm{RC})$ & 1.00 & 1.00 & 0.00 & 1.00 & 1.00 & 0.00 \\
\hline Needs permission for FP & 1.372 & $1.421 \dagger$ & $0.175 \dagger$ & $1.446^{\star}$ & 1.222 & 0.082 \\
\hline \multicolumn{7}{|l|}{ Prior contraceptive use } \\
\hline No (RC) & 1.00 & 1.00 & 0.00 & 1.00 & 1.00 & 0.00 \\
\hline Yes & 1.101 & 0.875 & -0.062 & 3.059 *** & $2.047^{\star \star \star}$ & $0.352^{\star * \star}$ \\
\hline \multicolumn{7}{|l|}{ Household wealth quintile } \\
\hline Lowest (RC) & 1.00 & 1.00 & 0.00 & 1.00 & 1.00 & 0.00 \\
\hline Second & 1.388 & 1.471 & 0.161 & 0.900 & 0.840 & -0.071 \\
\hline Middle & 1.272 & 1.306 & 0.108 & $0.734^{\star}$ & $0.687^{*}$ & $-0.152^{*}$ \\
\hline Fourth & 0.860 & 0.851 & -0.064 & 0.811 & 0.765 & -0.105 \\
\hline Highest & 1.341 & 1.268 & 0.080 & $0.589^{* *}$ & $0.481^{\star \star \star}$ & $-0.269^{\star \star \star}$ \\
\hline \multicolumn{7}{|l|}{ Dimensions of Ideation } \\
\hline Self-efficacy dimension & --- & $1.533^{\star \star \star}$ & $0.391^{\star \star \star}$ & --- & 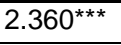 & 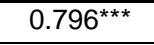 \\
\hline Myths and rumors dimension & $\begin{array}{ll}-- \\
\end{array}$ & 1.194 & 0.158 & --- & $1.407^{\star \star \star}$ & $0.322^{\star \star \star}$ \\
\hline $\begin{array}{l}\text { Social interactions and influence } \\
\text { dimension }\end{array}$ & --- & 1.100 & 0.085 & --- & $1.324^{\star \star \star}$ & $0.264^{\star \star \star}$ \\
\hline $\begin{array}{l}\text { Contraceptive awareness } \\
\text { dimension }\end{array}$ & --- & 1.016 & 0.015 & --- & $1.214^{\star \star}$ & $0.164^{\star \star}$ \\
\hline
\end{tabular}

Notes: RC= Reference Category. --- = Not applicable. Statistical significance: $\dagger p<0.1{ }^{\star} p<0.05^{* \star} p<0.01{ }^{\star \star \star} p<0.001$.

Model 1 includes only socio-demographic and household correlates.

Model 2 includes all the variables in Model 1 and the four dimensions of ideation. 


\subsubsection{Nigeria}

Only $13.8 \%$ (95\% CI: $12.5 \%, 15.1 \%)$ of married or cohabiting women not currently using a modern method reported the intention to do so in the next 12 months. Contraceptive intention varied by city, from $11.5 \%$ in Kaduna to $21.1 \%$ in Abuja (Table not shown).

The results of Model 1 (Table 3) indicate a positive albeit non-graduated relationship with education and a strong concave relationship with age. Parity was positively associated with intention to use, with each additional child increasing the odds of intention to use by about $10 \%$. The odds of intention to use contraception also varied by city of residence. Specifically, the women resident in Ibadan, Kaduna, or Zaria were less likely than their counterparts from Abuja to report an intention to use in the next 12 months. Desires for no additional child increased the odds of contraceptive intention more than threefold. Similarly, prior use of contraceptives increased the odds of intention to use more than threefold. The model also revealed a strong positive association with husband's education and a negative, albeit weak, relationship with religiosity. The relationship with women's autonomy was not as expected, as the women who reported that they needed permission to use contraceptives were more likely than others to report an intention to use contraception. The relationship with household wealth was unexpectedly negative.

With the introduction of ideational factors into the estimated model (see Model 2) the pattern of relationships with most of the socio-demographic and household variables is similar to what we observed in Model 1. However, a few variables become either less significant or non-significant, including education and women's autonomy. By contrast, being Muslim is now significantly associated with greater intention to use. All four dimensions of ideation are significantly associated with contraceptive use intention. A higher score for perceived self-efficacy and greater rejection of myths and rumors are associated with increased odds of reporting contraceptive intention. We also find that women who have higher scores on the social interaction and influence dimension and women with higher contraceptive awareness are significantly more likely to intend to use contraceptives than their counterparts with lower scores. A comparison of the standardized beta coefficients revealed that self-efficacy was, by far, the most important dimension of ideation affecting contraceptive use intention in Nigeria. 


\section{Discussion}

Recognizing the role of ideation in contraceptive use and intention to use, this study identified the relevant dimensions of contraceptive ideation in urban areas of Kenya (a country with a moderate level of contraceptive prevalence and considerable unmet need) and Nigeria (a country where contraceptive prevalence and unmet need remain low, and fertility desires are high). We also explored the association of the various dimensions of ideation with contraceptive use intentions. To the best of our knowledge, this is the first study that explicitly examines the dimensionality of ideation in relation to contraceptive use intentions.

In spite of the differences in contraceptive prevalence and reproductive health outcomes between Kenya and Nigeria, there are striking similarities in the dimensions of ideation and in the relationship between ideation and contraceptive use intentions in the two countries. Our study identified four dimensions of contraceptive ideation in both countries: perceived self-efficacy, myths and rumors related to contraceptives, social interactions and influence, and awareness about contraceptive methods.

There are commonalities and differences in the association of these dimensions of ideation with contraceptive use intention in Kenya and Nigeria. All four dimensions of ideation turned out to be very strong predictors in Nigeria, whereas in Kenya only the self-efficacy dimension was significant. Nonetheless, in both countries the self-efficacy dimension was by far the most significant ideational predictor of intention to use contraception. The importance of self-efficacy for contraceptive use intention in both countries is consistent with evidence from prior research (Agha 2010; Bogale, Boer, and Seydel 2010; Taffa et al. 2002; Khumsaen and Gary 2009; Ryan, Franzetta, and Manlove 2007).

This study identified other important correlates of intention to use contraception; some of these correlates are common to both countries whereas others are relevant to only one. For example, parity is consistently associated with intention to use contraception in both countries. The finding that the odds of contraceptive use intention increase with parity may suggest that women in both countries tend to wait until they have a specific number of children before considering contraception. This relationship is understandable in a context where many people believe that contraceptives may hinder the attainment of future fertility goals.

Nigeria and Kenya differ in some noticeable ways in terms of the key sociodemographic correlates of contraceptive intentions. For example, in Nigeria, after controlling for ideation, age of the woman was a significant, albeit concave, predictor of intention to use contraceptives. By contrast, in Kenya there was no strong relationship between age and contraceptive intention. In other words, in Nigeria where contraceptive use is generally low and desires for large family sizes widespread, the non- 
contracepting women most likely to intend to use a method are those in the middle childbearing ages. By contrast, in Kenya where contraceptive prevalence is much higher but with a relatively high level of unmet need, intention to use a method no longer appears to be so much a function of the woman's age. Another striking difference between Nigeria and Kenya has to do with the role of fertility desires. In Nigeria, women who do not want any (more) children were significantly more likely to intend to use than women wanting more children: this relationship was absent in Kenya. In addition, Kenya and Nigeria differ regarding the significance of husband/partner's education. This variable is a strong predictor in Nigeria but is not associated with the outcome in Kenya. Contrary to evidence from some prior studies, this study did not show a strong association between education of the woman and contraceptive use intention in Kenya or Nigeria after controlling for ideation (Meskele and Mekonnen 2014; Dibaba 2009; Adegbola and Okunowo 2007). Whereas the lack of a significant association between education and intention to use contraception is unexpected, it is consistent with what a few studies have found in other contexts (Agha 2010; Gebremariam and Addissie 2014).

Prior studies have documented the positive association between women's decisionmaking autonomy and contraceptive use or intention (Callahan and Becker 2013; Hogan, Berhanu, and Hailemariam 1999; Saleem and Bobak 2005). In general, these studies have found that greater decision-making autonomy is associated with higher odds of contraceptive use and intention. In contrast to these studies, there is no evidence of a strong relationship between women's autonomy and contraceptive use intention in Kenya. In Nigeria, the surprising positive relationship between lack of autonomy and intention to use contraceptive disappeared after controlling for ideation. The reason for this finding is unclear, although it is possible that any relationship between women's autonomy and contraceptive intentions operates through its (women's autonomy) link with ideation.

In both countries, we found significant differences in contraceptive intentions across cities, pointing to the importance of the context in which women live. Whereas household wealth does not appear to make a significant difference to contraceptive intention in Kenya, there are significant wealth inequalities in Nigeria, although not in the expected direction. Indeed, it is not clear why wealthier women in Nigeria were less likely to report contraceptive intention than their poorer counterparts.

Findings from this study have implications for family planning promotional efforts. The important role of ideation in contraceptive use intention identified in this study indicates that an ideation framework is relevant in developing strategies for generating demand for family planning services and increasing contraceptive prevalence. More specifically and in relation to the two study countries, communication programs should focus on increasing self-efficacy for contraceptive use. The literature 
on self-efficacy is rich with suggestions for strengthening this construct. Bandura (1977) specified four channels through which self-efficacy can be learned and strengthened: (1) successful performance of the behavior (enactive source); (2) modeling or vicarious experience (vicarious source); (3) persuasion or encouragement from others (exhortative source); and (4) emotional arousal (emotive source). Substantively, consistent with the enactive source of self-efficacy, strategies for strengthening self-efficacy for contraceptive use should include encouraging clients to use contraceptives for the first time and develop mastery of the practice. In this respect, it is critical to identify and address psychological, logistic, and structural barriers to contraceptive access. Also, based on the self-efficacy items explored in this study, it is important to provide opportunities for women to learn and practice how to communicate with their spouses on contraceptive use. In line with the vicarious source of self-efficacy, relevant strategies should include opportunities for the audience to learn from a satisfied contraceptive user similar in other respects to the non-using audience. According to Bandura, observing relevant behaviors in others allows one to form "a conception of how new behavior patterns are performed, and on later occasions the symbolic construction serves as a guide for action" (Bandura 1977: 192). Modeling relevant behaviors can be implemented in small groups or through the mass media. Strategies reflecting the exhortative source of self-efficacy could include promoting discussion about contraceptive use with significant others and encouraging personal advocacy in favor of contraceptive use among the intended audience. Finally, consistent with the emotive source of self-efficacy, programs should include strategies for reducing audience anxiety about contraceptives by addressing fears and misconceptions.

The need for addressing fears and misinformation about contraceptives is further supported by our study finding that the myths and rumors dimension of ideation is a very strong predictor of contraceptive use intention in Nigeria. Effectively correcting myths and rumors about contraceptives will require strategically designed messages that provide factual information on contraceptives and debunk rumors. The mass media can be used to convey such messages. However, it is important to include the use of small group interventions that allow participants to discuss the prevailing myths about contraceptives in their community and critically examine their personal beliefs about contraceptives.

Our finding that shows that women who do not want any (more) children in Nigeria are more likely to intend to use contraception suggests that efforts that focus on promoting the small family as the norm are relevant in Nigeria. Such efforts might be redundant in Kenya. The findings also support efforts to better understand why Moslems in Kenya and Christians in Nigeria seem to be at a disadvantage, and targeting 
these groups accordingly. In either country, efforts that use places of worship as a forum and religious leaders as a vehicle for reaching the intended audience are relevant.

This study has demonstrated the importance of ideation in helping individuals form the intention to use modern contraceptives. The Kincaid model is particularly relevant in this context, although our study suggests that the cognitive domain is not necessarily a one-dimensional construct. In our analysis, contraceptive awareness (knowledge) and myths and rumors (attitudes) load on separate factors in both countries.

One of the reasons we decided to focus on contraceptive intentions in this study is because there is considerable evidence that contraceptive intentions strongly predict contraceptive use (Curtis and Westoff 1996; Bankole and Westoff 1998; Roy et al. 2003). Nonetheless, it is also true that intention does not always translate into behavioral performance. For example, a study in Bali, Indonesia, found that almost 30\% of the women who reported intention not to have any more children had a child during the four-year study period (Withers, Tavrow, and Abe 2012). In a meta-analysis of existing meta-analytic reviews, Sheeran (2002) found that although the effects of intention on behavior are relatively large, only $28 \%$ of the variance in behavior is explained by intention. So, for non-contracepting women, developing the intention to use contraceptives is not a guarantee that these women will eventually adopt a method. Efforts will still need to be geared towards helping these women translate their contraceptive intentions into reality. Fortunately, there is guidance from extant literature regarding how to maximize the likelihood that intentions will be translated into behavior. Research has shown that the consistency of intention and behavior depends on the type of intention formed, goal intention or implementation intention (Fennis et al. 2011; Gollwitzer and Sheeran 2006; Sheeran 2002). Whereas goal intention relates to what people plan to do sometime in the future, implementation intention is more specific in terms of the time and context of implementation of the behavior (Sheeran 2002). Literature has shown that implementation intentions are more likely to be translated into behavior than goal intentions. Other studies have highlighted the role of self-efficacy in bridging the intention-behavior gap (Lippke et al. 2009; Schwarzer 2008; Sniehotta, Scholz, and Schwarzer 2005). In sum, strategies for bridging the intention-behavior gap should include the use of persuasive messages that encourage the audience to form specific time-bound intentions to use contraceptives, and efforts to strengthen self-efficacy for action.

This study has some limitations that warrant mention. First, the data analyzed are self-reported. There is therefore the possibility that the responses might have been affected by social desirability bias. During data collection the field-workers took appropriate steps to minimize subjectivity and the influence of social desirability, including interviewing participants in a private location in the absence of a third party, 
assuring the respondent of confidentiality, and minimizing social distance between the interviewer and the interviewee. The second limitation has to do with the variable derived from the questions on perceived need for permission and perceived social support. It is possible that women misperceive whether they actually need permission from their husbands, or whether they actually have the support that they think they have regarding contraceptive use. Third, the study relies on cross-sectional data, thereby making causal inference problematic. Nonetheless, the consistency and strength of the association of ideation with contraceptive intention lend support to the argument that the observed relationships are not trivial. The implications of the findings for programming should therefore be taken seriously.

\section{Conclusion}

This study provides strong evidence of the relevance of the ideation model in contraceptive use research and programing in urban areas of two African countries with different levels of contraceptive prevalence, unmet need, and fertility desires. One dimension of ideation was particularly influential in predicting intention to use in both countries: self-efficacy. Programs seeking to increase contraceptive use and help women and couples to attain their desired family size should promote contraceptive self-efficacy. 


\section{References}

Abbasi-Shavazi, M.J., McDonald, P., and Hosseini-Chavoshi, M. (2009). The Fertility Transition in Iran: Revolution and Reproduction. New York: Springer. doi:10.1 007/978-90-481-3198-3.

Adegbola, A. and Okunowo, A. (2007). Intended postpartum contraceptive use among pregnant and puerperal women at a university teaching hospital. Archives of Gynecology and Obstetrics 280(6): 987-992. doi:10.1007/s00404-009-1056-6.

Agha, S. (2010). Intentions to use contraceptives in Pakistan: implications for behavior change campaigns. BMC Public Health 10(1): 450. doi:10.1186/1471-2458-10450 .

Agha, S. and Van Rossem, R. (2004). Impact of a school-based peer sexual health intervention on normative beliefs, risk perceptions, and sexual behavior of Zambian adolescents. Journal of Adolescent Health 34(5): 441-452. doi:10.1016 /S1054-139X(03)00331-8.

Ahmed, S., Li, Q., Liu, L., and Tsui, A.O. (2012). Maternal deaths averted by contraceptive use: an analysis of 172 countries. The Lancet 380(9837): 111-125. doi:10.1016/S0140-6736(12)60478-4.

Amouzou, A. and Becker, S. (2009). Effects of economic status and family planning ideation on married women's fertility intentions in Ghana and Kenya. Paper presented at the International Conference on Family Planning Research and Best Practices, Kampala, Uganda, November 15-18, 2009.

Babalola, S. and Kincaid, D.L. (2009). New Methods for Estimating the Impact of Health Communication Programs. Communication Methods and Measures 3(12): 61-83. doi:10.1080/19312450902809706.

Babalola, S. and Vonrasek, C. (2005). Communication, ideation and contraceptive use in Burkina Faso: An application of the propensity score matching method. The Journal of Family Planning and Reproductive Health Care 31(3): 207-212. doi:10.1783/1471189054484022.

Bajwa, S.K., Bajwa, S.J.S., Ghai, G.K., Singh, K., and Singh, N. (2012). Knowledge, Attitudes, Beliefs, and Perception of the North Indian Population Toward Adoption of Contraceptive Practices. Asia Pacific Journal of Public Health 24(6): 1002-1012. doi:10.1177/1010539511411473.

Bandura, A. (1977). Self-efficacy: Toward a unifying theory of behavioral change. Psychological Review 84(2): 191-215. doi:10.1037/0033-295X.84.2.191. 
Bankole, A. and Westoff, C.F. (1998). The consistency and validity of reproductive attitudes: Evidence from Morocco. Journal of Biosocial Sciences 30(4): 439455. doi:10.1017/S0021932098004398.

Bogale, G.W., Boer, H., and Seydel, E.R. (2010) Condom use among low-literate, rural females in Ethiopia: the role of vulnerability to HIV infection, condom attitude, and self-efficacy. AIDS Care 22(7): 851-857. doi:10.1080/09540120903483026.

Bongaarts, J. and Watkins, S.C. (1996). Social Interactions and Contemporary Fertility Transitions. Population and Development Review 22(4): 639-682. doi:10.2307/2 137804.

Bosompra, K. (2001). Determinants of condom use intentions of university students in Ghana: An application of the theory of reasoned action. Social Science and Medicine 52(7): 1057-1069. doi:10.1016/S0277-9536(00)00213-6.

Bryant, K.D. (2009). Contraceptive use and attitudes among female college students. The ABNF journal: official journal of the Association of Black Nursing Faculty in Higher Education 20(1): 12-16.

Callahan, R.L. and Becker, S. (2013). Contraceptive Intentions and Use in Rural Bangladesh. Paper presented at the Annual Meeting of the Population Association of America, April 11-13, 2013. [http://paa2013.princeton.edu/paper s/130056]

Cleland, J. (1985). Marital fertility decline in developing countries: theories and the evidence. In: Cleland, J., Hobcraft, J., and Dinesen, B. (eds.). Reproductive Change in Developing Countries: Insights from the World Fertility Survey. New York: Oxford University Press: 223-252.

Cleland, J., Conde-Agudelo, A., Peterson, H., Ross, J., and Tsui, A.O. (2012). Contraception and health. The Lancet 380(9837): 149-156. doi:10.1016/S0140-6 736(12)60609-6.

Cleland, J. and Wilson, C. (1987). Demand Theories of the Fertility Transition: An Iconoclastic View. Population Studies: A Journal of Demography 41(1): 5-30.

Curtis, L. and Westoff, C.F. (1996). Intention to use contraceptives and subsequent contraceptive behavior in Morocco. Studies in Family Planning 27(5): 239-250. doi:10.2307/2137996.

Dibaba, Y. (2009). Factors Influencing Women's Intention to Limit Child Bearing in Oromia, Ethiopia. Ethiop.J.Health Dev 22(3): 28-33. doi:10.4314/ejhd.v23i1.44 834. 
Fennis, B.M., Adriaanse, M.A., Stroebe, W., and Pol, B. (2011). Bridging the intention-behavior gap: Inducing implementation intentions through persuasive appeals. Journal of Consumer Psychology 21(3): 302-311. doi:10.1016/j.jcps.20 10.12.003.

Fishbein, M., Triandis, H.C., Kanfer, F.H., Becker, M.H., Middlestadt, S.E., and Eichler, A. (2001). Factors influencing behavior and behavior change. In: Baum, A., Revenson T.R., and Singer, J.E. (eds.). Handbook of Health Psychology. Hillsdale, NJ: Lawrence Erlbaum: 3-17.

Gayen, K. and Raeside, R. (2010). Social networks and contraception practice of women in rural Bangladesh. Social Science and Medicine 71(9): 1584-1592. doi:10.1016/j.socscimed.2010.08.002.

Gebremariam, A. and Addissie, A. (2014). Intention to use long acting and permanent contraceptive methods and factors affecting it among married women in Adigrat town, Tigray, Northern Ethiopia. Reproductive health 11(1): 24. doi:10.1186/17 42-4755-11-24.

Gollwitzer, P.M. and Sheeran, P. (2006). Implementation Intentions and Goal Achievement: A Meta-analysis of Effects and Processes. Advances in Experimental Social Psychology 38: 69-119. doi:10.1016/s0065-2601(06) 38002-1.

Hogan, D.P., Berhanu, B., and Hailemariam, A. (1999). Household Organization, Women's Autonomy, and Contraceptive Behavior in Southern Ethiopia. Studies in Family Planning 30(4): 302-314. doi:10.1111/j.1728-4465.1999.t01-2-.x.

Kaggwa, E.B., Diop, N., and Storey, J. D. (2008). The Role of Individual and Community Normative Factors: A Multilevel Analysis of Contraceptive Use Among Women in Union in Mali. International Family Planning Perspectives 34(2): 79-88. doi:10.1363/3407908.

Kavanaugh, M.L. and Anderson, R.M. (2013). Contraception and Beyond: The Health Benefits of Services Provided at Family Planning Centers. New York: Guttmacher Institute.

Kenya National Bureau of Statistics (KNBS) and ICF Macro. (2010). Kenya Demographic and Health Survey 2008-09. Calverton, MD: KNBS and ICF Macro.

Khumsaen, N. and Gary, F.A. (2009). Determinants of Actual Condom Use Among Adolescents in Thailand. Journal of the Association of Nurses in AIDS Care 20(3): 218-229. doi:10.1016/j.jana.2008.12.006. 
Kincaid, D.L. (2000a). Mass Media, Ideation, and Behavior A Longitudinal Analysis of Contraceptive Change in the Philippines. Communication Research 27(6): 723763. doi:10.1177/009365000027006003.

Kincaid, D.L. (2000b). Social networks, ideation, and contraceptive behavior in Bangladesh: a longitudinal analysis. Social Science Medicine 50(2): 215-231. doi:10.1016/S0277-9536(99)00276-2.

Leroy-Beaulieu. (1896). Traité Théorique et Pratique d'Économie Politique. Paris: Librairie Guillaumin et Cie.

Lesthaeghe, R. (1983). A Century of Demographic and Cultural Change in Western Europe: An Exploration of Underlying Dimensions. Population and Development Review 9(3): 411-435. doi:10.2307/1973316.

Lesthaeghe, R. (2010). The Unfolding Story of the Second Demographic Transition. Population and Development Review 36(2): 211-251. doi:10.1111/j.1728-4457. 2010.00328.x.

Lesthaeghe, R. and Surkyn, J. (1988). Cultural Dynamics and Economic Theories of Fertility Change. Population and Development Review 14(1): 1-45. doi:10.2307/ 1972499.

Link, C.F. (2011). Spousal Communication and Contraceptive Use in Rural Nepal: An Event History Analysis. Studies in Family Planning 42: 83-92. doi:10.1111/j.17 28-4465.2011.00268.x.

Lippke, S., Wiedemann, A.U., Ziegelmann, J.P., Reuter, T., and Schwarzer, R. (2009). Self-efficacy Moderates the Mediation of Intentions Into Behavior via Plans. American Journal of Health Behavior 33(5): 521-529. doi:10.5993/AJHB. 33.5.5.

Meskele, M. and Mekonnen, W. (2014). Factors affecting women's intention to use long acting and permanent contraceptive methods in Wolaita Zone, Southern Ethiopia: A cross-sectional study. BMC women's health 14(1): 109. doi:10.1186/ 1472-6874-14-109.

Moreland, S. and Talbird, S. (2006). Achieving the Millennium Development Goals: The Contribution of Fulfilling the Unmet Need for Family Planning. Washington, DC: Constella Futures, POLICY Project.

National Population Commission (NPC) [Nigeria] and ICF International. (2014). Nigeria Demographic and Health Survey 2013. Abuja, Nigeria, and Rockville, MD: NPC and ICF International. 
National Population Commission (NPC) [Nigeria] and ICF Macro. (2009). Nigeria Demographic and Health Survey 2008. Abuja, Nigeria: National Population Commission and ICF Macro.

Potard, C., Courtois, R., Samedy, M.L., Mestre, B., Barakat, M.J., and Réveillère, C. (2012). Determinants of the intention to use condoms in a sample of French adolescents. The European Journal of Contraception and Reproductive Health Care 17(1): 55-64. doi:10.3109/13625187.2011.634455.

Rahayu, R., Utomo, I., and McDonald, P. (2009). Contraceptive Use Pattern among Married Women in Indonesia. Paper presented at the International Conference on Family Planning: Research and Best Practices, Kampala, Uganda, November 15-18 2009.

Roy, T.K., Ram, F., Nangia, P., Saha, U., and Khan, N. (2003). Can Women's Childbearing and Contraceptive Intentions Predict Contraceptive Demand? Findings from a Longitudinal Study in Central India. International Family Planning Perspectives 29(1): 25-31. doi:10.2307/3180998.

Ryan, S., Franzetta, K., and Manlove, J. (2007). Knowledge, Perceptions, and Motivations for Contraception: Influence on Teens' Contraceptive Consistency. Youth and Society 39(2): 182-208. doi:10.1177/0044118X06296907.

Saleem, S. and Bobak, M. (2005). Women's autonomy, education and contraception use in Pakistan: a national study. Reproductive Health 2(8). doi:10.1186/1742-4 755-2-8.

Samandari, G., Speizer, I. and O’Connell, K. (2010). The Role of Social Support and Parity in Contraceptive Use in Cambodia. International Perspectives on Sexual and Reproductive Health 36(3): 122-131. doi:10.1363/3612210.

Schwarzer, R. (2008). Modeling Health Behavior Change: How to Predict and Modify the Adoption and Maintenance of Health Behaviors. Applied Psychology 57(1): 1-29. doi:10.1111/j.1464-0597.2007.00325.x.

Sheeran, P. (2002) Intention-Behavior Relations: A Conceptual and Empirical Review. European Review of Social Psychology 12(1): 1-30. doi:10.1080/14792 772143000003.

Smith, R., Ashford, L., Gribble, J., and Clifton, D. (2009). Family planning saves lives. $4^{\text {th }}$ Edition. Washington, DC: Population Reference Bureau. 
Sniehotta, F.F., Scholz, U., and Schwarzer, R. (2005). Bridging the intention-behaviour gap: Planning, self-efficacy, and action control in the adoption and maintenance of physical exercise. Psychology and Health 20(2): 143-160. doi:10.1080/08870 440512331317670.

Sobotka, T., Zeman, K., and Kantorová, V. (2003). Demographic shifts in the Czech Republic after 1989: A second demographic transition view. European Journal of Population/Revue européenne de démographie 19(3): 249-277.

Sonfield, A., Hasstedt, K., Kavanaugh M.L., and Anderson, R. (2013). The social and economic benefits of women's ability to determine whether and when to have children. New York: Guttmacher Institute.

Taffa, N., Klepp, K.I., Sundby, J., and Bjune, G. (2002). Psychosocial determinants of sexual activity and condom use intention among youth in Addis Ababa, Ethiopia. International Journal of STD and AIDS 13(10): 714-719. doi:10.1258/ 095646202760326480.

Teye, J.K. (2013). Modern contraceptive use among women in the Asuogyaman district of Ghana: Is reliability more important than health concerns? African Journal of Reproductive Health 17(2): 58-71.

Tsui, A.O., McDonald-Mosley, R., and Burke, A.E. (2010). Family Planning and the Burden of Unintended Pregnancies. Epidemiologic Reviews 32(1): 152-174. doi:10.1093/epirev/mxq012.

Tumlinson, K., Speizer, I.S., Davis, J.T., Fotso, J.C., Kuria, P., and Archer, L.H. (2013). Partner Communication, Discordant Fertility Goals, and Contraceptive Use in Urban Kenya. African Journal of Reproductive Health 17(3): 79-90.

van de Kaa, D.J. (1996) Anchored Narratives: The Story and Findings of Half a Century of Research into the Determinants of Fertility. Population Studies: A Journal of Demography 50(3): 389-432. doi:10.1080/0032472031000149546.

van de Kaa, D.J. (2002). The idea of a second demographic transition in industrialized countries. Birth 35: 45.

Withers, M., Tavrow, P., and Abe, D. (2012) Who Meets Their Intentions to Stop Childbearing? Results of a Longitudinal Study in Rural Eastern Bali, Indonesia. Health Care for Women International 33(9): 814-832. doi:10.1080/07399332.20 11.585534 . 
Demographic Research: Volume 33, Article 8 